\title{
Loss of Hippocampal Serine Protease BSP1/Neuropsin Predisposes to Global Seizure Activity
}

\author{
Ben Davies, ${ }^{1}$ Ian R. Kearns, ${ }^{2}$ Jan Ure, ${ }^{1}$ Ceri H. Davies, ${ }^{2}$ and Richard Lathe ${ }^{1}$

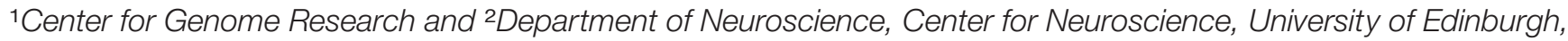 \\ Edinburgh EH9 3JQ, United Kingdom
}

\begin{abstract}
Serine proteases in the adult CNS contribute both to activitydependent structural changes accompanying learning and to the regulation of excitotoxic cell death. Brain serine protease 1 (BSP1)/neuropsin is a trypsin-like serine protease exclusively expressed, within the CNS, in the hippocampus and associated limbic structures. To explore the role of this enzyme, we have used gene targeting to disrupt this gene in mice. Mutant mice were viable and overtly normal; they displayed normal hippocampal long-term synaptic potentiation (LTP) and exhibited no deficits in spatial navigation (water maze). Nevertheless, electrophysiological studies revealed that the hippocampus of mice lacking this specifically expressed protease possessed an increased susceptibility for hyperexcitability (polyspiking) in response to repetitive afferent stimulation. Furthermore, seizure
\end{abstract}

activity on kainic acid administration was markedly increased in mutant mice and was accompanied by heightened immediate early gene (c-fos) expression throughout the brain. In view of the regional selectivity of BSP1/neuropsin brain expression, the observed phenotype may selectively reflect limbic function, further implicating the hippocampus and amygdala in controlling cortical activation. Within the hippocampus, our data suggest that BSP1/neuropsin, unlike other serine proteases, has little effect on physiological synaptic remodeling and instead plays a role in limiting neuronal hyperexcitability induced by epileptogenic insult.

Key words: brain serine protease; BSP1; cortex; epileptiform; fos; hippocampus; kainic acid; knock-out; long-term potentiation; LTP; mouse; mutant; neuropsin; seizure; targeting
Serine proteases fulfil diverse roles in the CNS. During development, they contribute to the dynamic rearrangement of the extracellular matrix, whereas, in the adult, their roles extend to (1) activating and processing neuropeptides, growth hormones, and neurotrophic factors, (2) structural plasticity associated with learning and memory processes, and (3) regulating neuronal survival and proliferation. This protease family has also been implicated in the pathophysiology of neurodegenerative disorders including Alzheimer's disease (Selkoe, 1991).

At the synaptic level, controlled proteolysis contributes to developmental remodeling of neuronal contacts and to memory consolidation (Bailey and Kandel, 1993). Specifically, tissue-type plasminogen activator (t-PA) has been suggested to play a pivotal role. t-PA contributes to developmental synaptogenesis (Vassalli et al., 1991) and is implicated in synaptic correlates of learning including long-term potentiation (LTP) (Frey et al., 1996; Huang et al., 1996; Baranes et al., 1998; Madani et al., 1999; Calabresi et al., 2000). Activity-dependent upregulation of t-PA production (Qian et al., 1993; Gualandris et al., 1996) may lead to plasminogen activation and proteolysis of the extracellular matrix (Chen

\footnotetext{
Received Dec. 27, 2000; revised May 21, 2001; accepted May 31, 2001.

This work was supported by the Medical Research Council and the Gatsby Charitable Foundation. We thank Richard Morris for helpful discussions, Mark Ramsay for assistance with behavioral analysis, and Louise Anderson and Janice Young for animal work.

Correspondence should be addressed to Dr. R. Lathe, Centre for Genome Research, University of Edinburgh, King's Buildings, West Mains Road, Edinburgh EH9 3JQ, UK. E-mail: rlathe@ed.ac.uk.

B. Davies's present address: Institut für Pharmakologie und Toxikologie, Universitätsklinikum Charité, Dorotheenstraße 94, 10117 Berlin, Germany.

C. H. Davies's present address: Department of Neuroscience, Glaxo-SmithKline Beecham Pharmaceuticals, New Frontiers Science Park North, Third Avenue, Harlow, Essex CM19 5AW, UK.

Copyright (C) 2001 Society for Neuroscience $\quad 0270-6474 / 01 / 216993-08 \$ 15.00 / 0$
}

and Strickland, 1997), thereby shaping long-lasting synaptic changes (Nakagami et al., 2000).

Serine proteases also regulate excitotoxic neuronal cell death. Mutant mice lacking t-PA, or plasminogen, are resistant to seizure induction and neuronal cell death after kainic acid injection (Tsirka et al., 1995, 1997). However, the role serine proteases fulfill in neurodegeneration is complex, and t-PA has also been reported to be neuroprotective (Vandenberghe et al., 1998; Kim et al., 1999). Such potentially paradoxical findings suggest complex regulation of neurodegeneration by serine proteases. This is indicated by studies on the serine protease inhibitor PN-1 in which either overexpression or loss increased sensitivity to excitotoxic cell death (Lüthi et al., 1997). These studies suggest that a delicate balance of proteolysis is required within the adult brain to maintain normal function; perturbations in this equilibrium can have profound effects on neuronal survival.

Perhaps reflecting this complex regulation, diverse members of the serine protease family are expressed in the CNS, notably in the hippocampus. In a systematic survey of family members expressed within this formation, we identified a novel trypsin-like protease, brain serine protease 1 (BSP1), that was strikingly restricted to the rat hippocampal CA1 and CA3 subfields, with some expression in adjacent entorhinal cortex (Davies et al., 1998). The mouse ortholog neuropsin is also prominently expressed in the hippocampus, although expression was also detected in the amygdala and other limbic structures (Chen et al., 1995). Outside the CNS, neuropsin levels are high in the skin, particularly during embryogenesis, and at lower levels in a variety of other organs throughout development (Chen et al., 1998).

The abundance and restricted expression of brain BSP1/ neuropsin in the hippocampus and associated brain regions suggest that BSP1/neuropsin may play a role in shaping neu- 
ronal excitability associated with neurodegenerative and mnemonic processes. To explore this possibility, we have developed mutant mice in which the BSP1/neuropsin gene has been disrupted. Homozygous mutant mice display an unusual phenotype, perhaps indicating that BSP1/neuropsin plays a specialized role in regulating hippocampal function in response to insult.

\section{MATERIALS AND METHODS}

Gene targeting in embryonic stem cells. Regions of the BSP1/neuropsin gene $5^{\prime}$ and $3^{\prime}$ of exon III were amplified from genomic DNA obtained from the embryonic day 14 (E14)-TG2a embryonic stem (ES) cell line using the Expand Long Range PCR system (Roche Products, Welwyn Garden City, UK). A 1.2 kb $5^{\prime}$ homology arm, encompassing exons I and II and the first and second introns, was amplified using primers $5^{\prime}$ dTGGTCGACCCCTAGCTCCATCCTCCAGCAAGACT-3' and 5'dTGGTCGACCTGGAGGCTATGATCACCCAGACGCA-3' corresponding to nucleotides $354-380$ and $728-853$ of the published mouse neuropsin cDNA sequence [accession number D30785; as revised from Chen et al. (1995)], respectively. A $4.5 \mathrm{~kb} 3^{\prime}$ homology arm, corresponding to the third and fourth intron and exons IV and V, was amplified using primers 5'-dGAGCGGCCGCATCATATCAGGCTGGGGCACTGT-3' and 5'-dGAGTCGACAGCATCCCGTCGCACACCAGA-3' corresponding to nucleotides $941-964$ and $1130-1151$ of the above sequence, respectively. The PCR conditions recommended by the supplier were used with an annealing temperature of $62^{\circ} \mathrm{C}$ and an elongation time of $5 \mathrm{~min}$ with a $20 \mathrm{sec} / \mathrm{cycle}$ increment for both sets of primers. Homology arms were subcloned into pBluescript KS around a $5 \mathrm{~kb}$ reporter/ selection cassette, comprising the lacZ reporter coding sequence prefixed by a viral IRES element and also containing a neomycin phosphotransferase gene under independent promoter control (MC1) and a polyadenylation sequence (Nehls et al., 1996) (see Fig. 1). The hybrid construct was suffixed by two copies of a herpes simplex virus thymidine kinase expression cassette (Smith et al., 1995) and transfected into E14-TG2a ES cells. Junction regions of the construct were confirmed by sequencing. Positive-negative selection (Mansour et al., 1988) was used to enrich for targeted clones. Colonies were screened by restriction enzyme digestion (EcoRV; HindIII) and by Southern blot hybridization to separate probes localized immediately $5^{\prime}$ and $3^{\prime}$ of the homology arms (see Fig. 1); the 5' and $3^{\prime}$ probes were also PCR amplified from genomic DNA using primers 5'-dCCCGCCCCTTGCATTCTGGAAGGT-3' and 5' -dAGTCTTGCTGGAGGATGGAGCTA-3' (corresponding to nucleotides 50-73 and 356-379 of the neuropsin cDNA sequence, respectively) and 5'dCCTCTGGTGTGCGACGGGATGCTCCA-3' and 5'-dCGAGATCTCGAGTCCCTGTTGTCCATGGTCTTCTTGA-3' (corresponding to nucleotides 1129-1154 and 1241-1268 of the neuropsin cDNA sequence, respectively). The $5^{\prime}$ probe recognized a $3.1 \mathrm{~kb}$ wild-type EcoRV fragment and a $1.8 \mathrm{~kb}$ targeted allele, whereas the $3^{\prime}$ probe recognized a 12 $\mathrm{kb}$ wild-type HindIII fragment and a $14 \mathrm{~kb}$ targeted allele.

Generation of transgenic mice. Targeted ES cell clones were injected into the blastocysts of strain C57BL/6 mice; chimeric males were mated to strain C57BL/6 females; typing of transgenic progeny was performed by Southern blotting using the probes described above or by PCR analysis of tail-tip DNA using an upstream primer hybridizing to exon II (5'dCGGAATTCCGACTGATCTGTGGGGGTGTCCTGGTTG-3', corresponding to nucleotides $651-676$ of the mouse neuropsin cDNA) and two downstream primers, one hybridizing to the $5^{\prime}$ end of the knocked-in reporter/selection cassette (5'-dCCCGGGATCATATCAGGCTGGGGCACTG-3') and the other hybridizing to a region of exon III deleted in the knock-out allele (5'-GACAGTGCCCCAGCCTGATATGATG$3^{\prime}$, corresponding to nucleotides 962-966 of the mouse cDNA sequence). By the use of these primers, a 650 bp band was amplified from the wild-type allele, and a 450 bp band was amplified from the transgenic allele, permitting both genotypes to be determined with a single PCR reaction $\left(30\right.$ cycles at $94^{\circ} \mathrm{C}, 60 \mathrm{sec} ; 60^{\circ} \mathrm{C}, 60 \mathrm{sec}$; and $72^{\circ} \mathrm{C}, 45 \mathrm{sec}$ ). Mice were systematically backcrossed against $\mathrm{C} 57 \mathrm{BL} / 6$ animals. To prepare homozygotes, littermates were intercrossed for each experiment.

Electrophysiology. In accordance with United Kingdom Home Office guidelines, mice were killed, and brains were dissected and placed in ice-cold artificial CSF (aCSF, $124 \mathrm{~mm} \mathrm{NaCl}, 3 \mathrm{~mm} \mathrm{KCl}, 1 \mathrm{mM} \mathrm{MgSO}_{4}$, $1.25 \mathrm{mM} \mathrm{NaH}_{2} \mathrm{PO}_{4}, 26 \mathrm{~mm} \mathrm{NaH} \mathrm{CO}_{3}, 2 \mathrm{mM} \mathrm{CaCl}_{2}$, and $10 \mathrm{~mm}$ D-glucose) saturated with $95 \% \mathrm{CO}_{2}-5 \% \mathrm{O}_{2}$. Transverse hippocampal slices $(350 \mu \mathrm{m})$ were prepared using a Campden vibroslicer and imme- diately transferred to a submersion-type chamber at $32^{\circ} \mathrm{C}$. Extracellular field potential responses were recorded using thin-walled glass microelectrodes $(1-5 \mathrm{M} \Omega$ ) filled with $4 \mathrm{M} \mathrm{NaCl}$ or aCSF placed in the stratum radiatum or stratum pyramidale in area CA1 of the hippocampus. Reproducible EPSPs or population spikes were evoked by repetitive afferent stimulation $(0.067 \mathrm{~Hz})$ in stratum radiatum using bipolar nickel-chromium electrodes. Late-phase LTP was induced by a series of four tetani each comprising $100 \mathrm{~Hz}$ for $1 \mathrm{sec}$ delivered $5 \mathrm{~min}$ apart. Paired-pulse stimulation and $1 \mathrm{~Hz}$ trains were generated using a Master 8 stimulator. Statistical analyses were performed on raw data using ANOVA.

Behavioral studies. Testing was performed in an open field water maze (diameter, $2 \mathrm{~m})$ filled with opaque water $\left(25 \pm 1^{\circ} \mathrm{C}\right)$ surrounded by visual cues with a submerged platform (diameter, $20 \mathrm{~cm}$ ). Swim paths were monitored with an overhead video camera connected to an image analyzer (HVS Image, Hampton, UK) and an Acorn (Framlingham, UK) computer, running software that sampled coordinates on-line at $10 \mathrm{~Hz}$ for subsequent automated data analysis. Mice were trained for two periods of $4 \mathrm{~d}$ with 4 trials/d (10 min intertest interval; maximum trial time of $120 \mathrm{sec}$, after which mice were guided to the platform). On day 5 the platform was removed, transfer tests of $60 \mathrm{sec}$ were performed, and the time spent in each quadrant was measured. BSP1/neuropsin knockout and wild-type littermate controls $(n=8 ; n=8)$ were coded; all experiments were performed blind.

Seizure studies. Kainic acid (Sigma, Poole, UK) in PBS was administered intraperitoneally at two doses $(15 \mathrm{mg} / \mathrm{kg} ; n=8, n=8$; and 30 $\mathrm{mg} / \mathrm{kg} ; n=8, n=10$ ) to BSP1/neuropsin knock-out and wild-type littermates. Mice were monitored for a period of $2-3 \mathrm{hr}$ after the injection. Baseline parameters were established with mice of each genotype injected with intraperitoneal PBS. In parallel, mice receiving 15 $\mathrm{mg} / \mathrm{kg}$ were killed at 2 and $48 \mathrm{hr}$ after the challenge for histological analysis. Mice receiving $30 \mathrm{mg} / \mathrm{kg}$ were killed at 30,90,120, and $240 \mathrm{~min}$ after the challenge.

In situ hybridization. A 370 bp region of the c-fos cDNA was amplified from brain cDNA using primers 5'-dCGGAGGAGGGAGCTGACAGATACACT-3' and 5'-dGCCTAGATGATGCCGGAAACAAGAA-3' and cloned into pBluescript (Stratagene, La Jolla, CA). Frozen tissue sections $(10 \mu \mathrm{m})$ were transferred to 2 -aminopropyltriethoxysilanecoated slides $\left[4 \%(\mathrm{w} / \mathrm{v})\right.$ paraformaldehyde, $\left.15 \mathrm{~min} ; 4^{\circ} \mathrm{C}\right]$, deproteinized $(20$ $\mu \mathrm{g} / \mathrm{ml}$ proteinase $\mathrm{K}, 1 \mathrm{~min}$; block with $0.2 \%$ glycine, $5 \mathrm{~min}$ ), acetylated $[0.25 \%$ acetic anhydride, $0.1 \mathrm{M}$ triethanolamine, $\mathrm{pH} 8$, and $0.8 \%(\mathrm{w} / \mathrm{v})$ $\mathrm{NaCl}, 10 \mathrm{~min}]$, dehydrated by passing through successively increasing ethanol solutions $\left(50-100 \%\right.$ ethanol), immersed in $\mathrm{CHCl}_{3}$, rinsed in ethanol, and air-dried. For hybridization, sections were incubated overnight at $55^{\circ} \mathrm{C}$ with ${ }^{35} \mathrm{~S}$-riboprobes (prepared by in vitro transcription from pBluescript and pretreated with $10 \mathrm{~mm}$ dithiothreitol) in buffer containing $50 \%$ (v/v) deionized formamide, $0.3 \mathrm{~m} \mathrm{NaCl}, 20 \mathrm{~mm}$ Tris-Cl, $\mathrm{pH}$ 8, 5 mm EDTA, $10 \mathrm{~mm} \mathrm{NaPO}_{4}, \mathrm{pH} \mathrm{8,10 \%}(\mathrm{w} / \mathrm{v})$ dextran sulfate, $1 \times$ Denhardt's solution, and $0.5 \mathrm{mg} / \mathrm{ml}$ yeast RNA. High-stringency washing $(2 \times \mathrm{SSC}$ and $0.1 \mathrm{M}$ dithiothreitol; $65^{\circ} \mathrm{C} ; 30 \mathrm{~min}$ ) was followed by RNase treatment (RNase A; $20 \mu \mathrm{g} / \mathrm{ml} ; 30 \mathrm{~min} ; 37^{\circ} \mathrm{C}$ ), washing, and dehydration through increasing ethanol concentrations. Slides were exposed for autoradiography (Kodak Biomax).

\section{RESULTS \\ Disruption of the mouse BSP1/neuropsin gene}

To address the role of the BSP1/neuropsin protease in hippocampal function, the gene encoding this enzyme was inactivated by homologous recombination in mouse ES cells. A region of exon III encoding the aspartic acid region of the catalytic site was deleted and replaced with a neomycin resistance gene, a $\beta$-galactosidase reporter gene, and translation termination codons in all three reading frames (Fig. $1 A$ ). The disruption of the BSP1/neuropsin gene was confirmed by genomic Southern blot analysis (Fig. $1 B$ ).

The insertion harbored a lacZ reporter cassette prefixed by an IRES element; chromogenic activity in heterozygous animals was used as a marker of the expression pattern of BSP1/neuropsin mRNA. However, analysis of whole brain revealed no significant staining in the hippocampus or any other brain regions. Furthermore, lacZ mRNA was not detected in the brains of heterozygous mice by in situ hybridization techniques (data not shown), sug- 


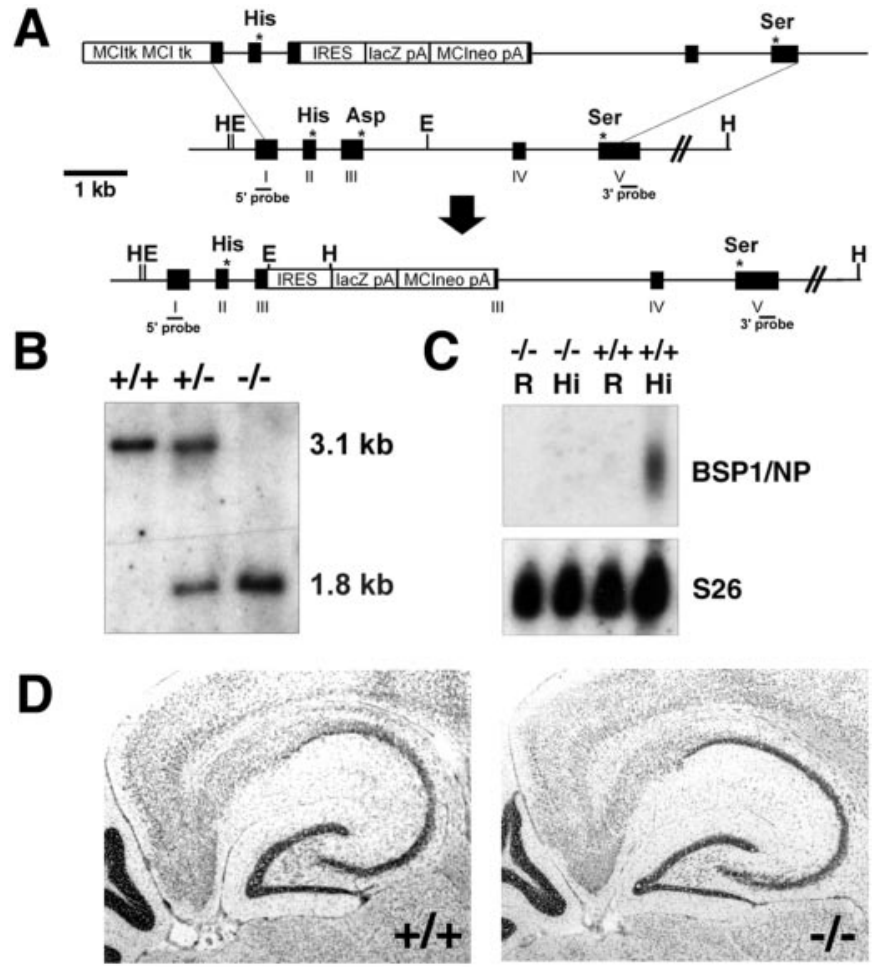

Figure 1. Targeted disruption of the murine BSP1/neuropsin locus. $A$, Structure of the targeting vector (top), wild-type BSP1/neuropsin allele (middle), and targeted allele (bottom) showing deletion of the catalytic aspartic acid residue region of exon III; asterisks indicate active site residues. A selection cassette ( $\mathrm{MC1} 1-\mathrm{neo}-\mathrm{pA})$, conferring resistance to G418 and a reporter cassette (IRES-lacZ-pA) allowing dicistronic translation of the bacterial $\beta$-galactosidase gene from the targeted allele were inserted. Two copies of a herpes simplex virus thymidine kinase gene (MC1-tk) were included in the vector for selection against nonhomologous integration. BSP1/neuropsin coding regions are indicated by filled boxes; the position of EcoRV $(E)$ and HindIII $(H)$ restriction sites and the probe used for the $5^{\prime}$ targeting screen are shown. $B$, Southern blot analysis of tail genomic DNA from wild-type $(+/+)$, heterozygous $(+/-)$, and homozygous knock-out $(-/-)$ animals demonstrating disruption of the BPS1/neuropsin gene. The probe hybridizes to a $3.1 \mathrm{~kb}$ EcoRV wild-type fragment and a $1.8 \mathrm{~kb} E c o \mathrm{RV}$ fragment from the targeted allele. C, Top, Northern blot analysis of total RNA of the hippocampus $(\mathrm{Hi})$ and rest of the brain $(R)$ from BSP1/neuropsin mutant animals $(-/-)$ and wild-type littermates $(+/+)$ hybridized with the BSP1/neuropsin cDNA. Bottom, The same blot hybridized with S26 ribosomal protein cDNA demonstrating equal loading of the blot. $D$, Photomicrograph of cresyl violet-stained horizontal sections through the hippocampus and entorhinal cortex of wild-type $(+/+$; left $)$ and BSP1/neuropsin mutant $(-/-$; right $)$ animals.

gesting that the BSP1-IRES-lacZ fusion downregulates or destabilizes the hybrid transcript. However, in skin, in which significant BSP1/neuropsin expression has been recorded previously (Chen et al., 1998), lacZ mRNA and reporter activity were readily detected in tissue from heterozygous animals but not from wildtype littermate controls (data not shown).

Heterozygote intercrosses produced animals homozygous for the gene disruption. Northern blot analysis of brain mRNA confirmed the absence of BSP1/neuropsin transcripts in mutant animals (Fig. 1C). Homozygous animals were born at the expected Mendelian ratio and displayed no obvious health, growth, or fertility abnormalities. Furthermore, despite the reported expression of BSP1/neuropsin during development, histological analysis of adult hippocampus as well as other brain regions failed to demonstrate any obvious changes in histoarchitecture (Fig. 1D).

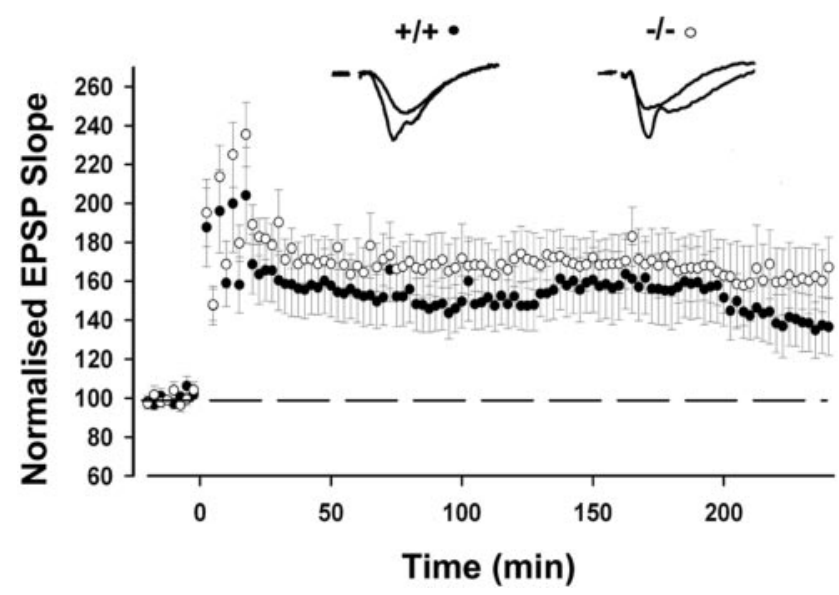

Figure 2. LTP in BSP1/neuropsin mutant and control mice. Graph showing the field EPSP slope expressed as a percentage of control responses over time. All data points represent 5-10 averaged fEPSPs; error bars indicate SEM. At time 0, four trains of stimulation (100 shocks at $100 \mathrm{~Hz}$; interstimulus interval, $5 \mathrm{~min}$ ) were delivered to the Schaffer collateral-commissural pathway. Closed circles represent pooled data from wild-type control mice, and open circles represent BSP1/neuropsin mutant pooled data. Insets, Synaptic traces representing two superimposed field EPSPs recorded in the stratum radiatum of area CA1 in response to single-shock stimulation in the same dendritic field immediately before tetanic stimulation and $3 \mathrm{hr}$ after conditioning in hippocampal slices taken from wild-type (left) and BSP1/neuropsin -/- (right) mice.

\section{Long-term potentiation is unaltered in BSP1/neuropsin mutant mice}

In the absence of any overt phenotype, we inspected neuronal function in the mutant mice in more detail. Serine proteases have been implicated in late-phase LTP, perhaps by facilitating structural changes at the synapse that contribute to the longevity of potentiation. BSP1/neuropsin expression is most prominent in the hippocampus; accordingly we analyzed slices prepared from BSP1/neuropsin knock-out mice and wild-type littermate controls for the extent of CA1 LTP induced by four consecutive tetani (each comprising $100 \mathrm{~Hz}$ for $1 \mathrm{sec}$ ) delivered 5 min apart. Baseline recordings revealed the absence of any gross modification of glutamatergic synaptic transmission (below) and the resting membrane potential; cell input resistance and spike frequency adaptation of CA1 pyramidal neurons were unchanged by BSP1 deletion (data not shown). Furthermore, no significant differences in the magnitude or profile of LTP induced in hippocampal slices prepared from each group of animals were observed at any time point after tetanization $(p>0.05)$, although there was an apparent trend for elevated LTP in BSP1/neuropsin knock-out slices (Fig. 2). The slope of the potentiated field EPSP (fEPSP) measured $4 \mathrm{hr}$ after tetanization in BSP1/neuropsin knock-out slices was $167 \pm 15 \%$ of control $(n=7)$, whereas that in wild-type slices was $136 \pm 15 \%$ of control $(n=7)$.

\section{BSP1/neuropsin mutant animals perform normally in the water maze}

The absence of a clear change in LTP in BSP1/neuropsin knockout animals does not exclude the possibility that this serine protease might affect learning and/or memory processes in vivo. To examine this we compared the performance of wild-type and BSP1/neuropsin mutant animals in the water maze spatial reference memory task (Morris et al., 1982). Animals placed in a 2-m-diameter pool were required to learn the location of a submerged platform using visual cues outside the maze. Learning 

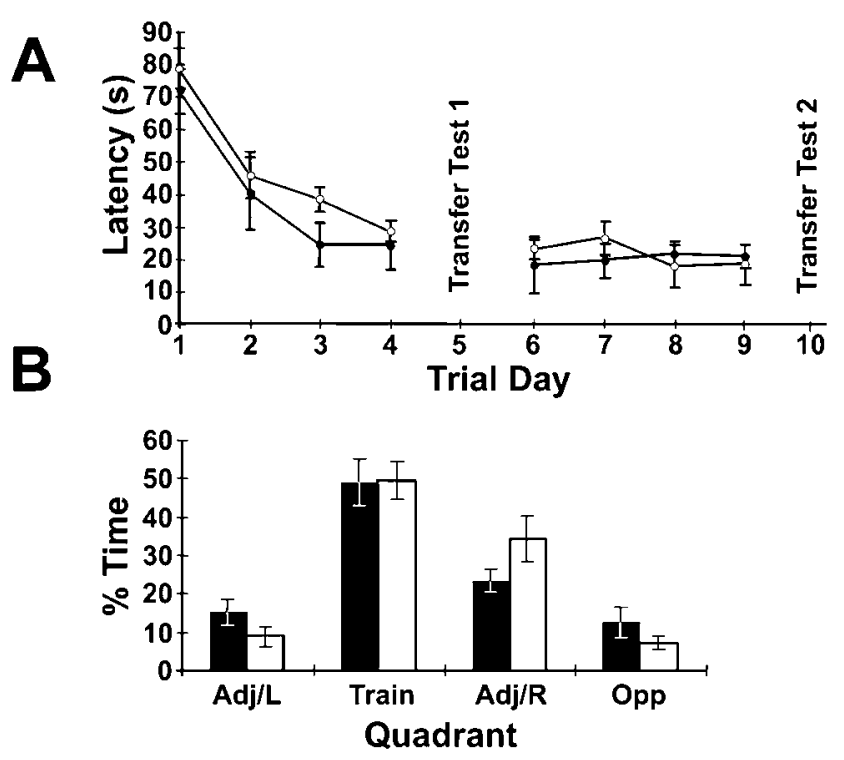

Figure 3. Spatial reference memory in BSP1/neuropsin mutant and control mice. $A$, Graph showing the mean latency of escape of BSP1/neuropsin mutant mice (open circles; $n=8$ ) and wild-type littermate controls (closed circles; $n=8$ ) against trial day. Both groups show a significant interaction between latency and trial day, indicating learning (ANOVA, $p<0.05)$. No significant interaction between latency and genotype was found (ANOVA, $p>0.05$ ). $B$, Results of the second transfer test showing the average percentage of time spent in the training quadrant (Train) and the adjacent right $(A d j / R)$, adjacent left $(A d j / L)$, and opposite $(O p p)$ quadrants for BSP1/neuropsin mutant animals (open vertical bar) and wild-type littermate controls (solid vertical bar). A pronounced preference for the training quadrant is demonstrated in both groups (ANOVA, $p<$ 0.05 ) but with no significant difference between genotypes (ANOVA, $p>$ $0.05)$.

occurred over the first and second $4 \mathrm{~d}$ periods of training in both mutant and wild-type groups. No significant differences in escape latency were observed (Fig. 3A). After $4 \mathrm{~d}$ of training, the platforms were removed; animals were examined for any learned preference for the quadrant in which the platform had been located previously. A spatial bias developed for the trained quadrant in all animals; no significant differences in the performance of wild-type and mutant groups were observed (Fig. 3B).

\section{Increased polyspiking in slices from BSP1/neuropsin-deficient mice}

Serine proteases are implicated in regulating the balance between synaptic excitation and inhibition; such changes may not necessarily relate to effects on LTP. Despite the lack of obvious changes in LTP and spatial reference memory, we therefore investigated the excitability of hippocampal slices from mutant and wild-type animals during repetitive stimulation that induces transient activity-dependent alterations in transmembrane ionic gradients (e.g., $\mathrm{K}^{+}$) and both glutamatergic and GABAergic (both $\mathrm{GABA}_{\mathrm{A}}$ and $\mathrm{GABA}_{\mathrm{B}}$ receptor-mediated) synaptic strength. In particular, the potential for hippocampal slices to exhibit polyspike discharges (EPSPs generating multiple population spikes) in response to $1 \mathrm{~Hz}$ stimulation for $30 \mathrm{sec}$ was investigated.

Irrespective of the genotype of the slice, repetitive stimulation (30 shocks at $1 \mathrm{~Hz}$ ) of the Schaffer collateral-commissural pathway induced polyspiking. However, throughout the period of afferent stimulation, it was apparent that in slices prepared from the BSP1/neuropsin mutant animals the extent of polyspiking was

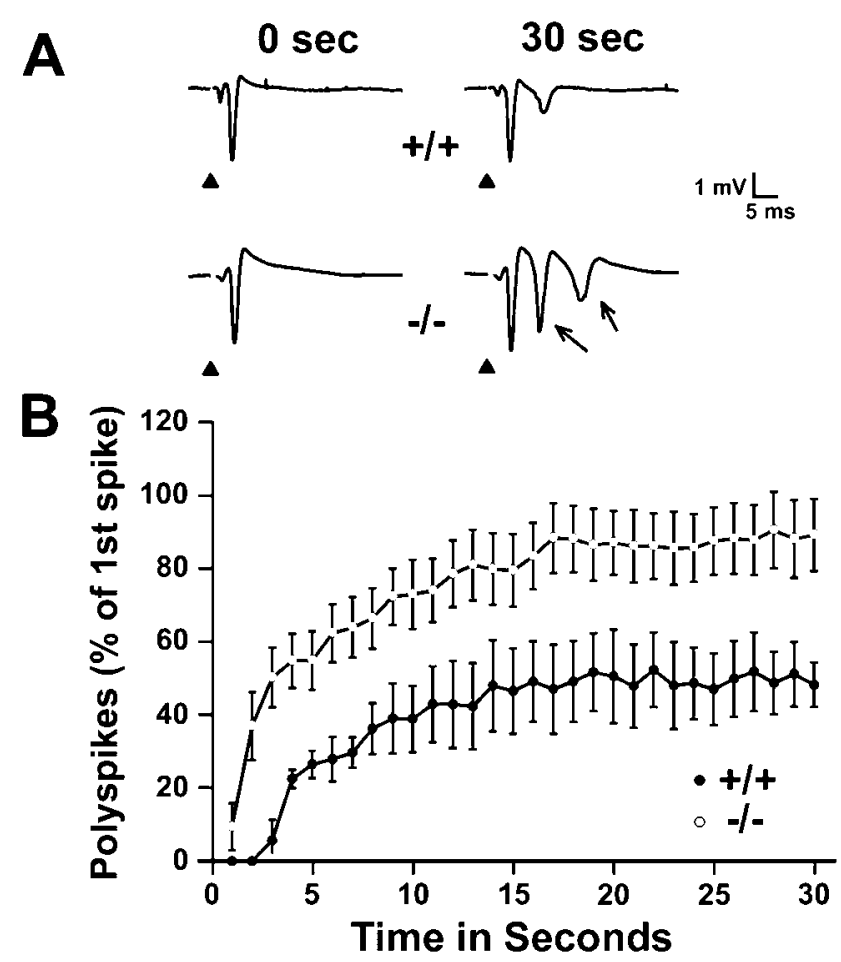

Figure 4. Polyspiking in slices from BSP1/neuropsin-deficient mice. $A$, Example of population spikes evoked by stimulation of the Schaffer collaterals recorded in the stratum pyramidale of the CA1 in BSP1/ neuropsin knock-out mice $(-/-$; bottom $)$ and wild-type littermate controls $(+/+;$ top $)$. Traces shown are before and immediately after repetitive stimulation $(1 \mathrm{~Hz} ; 30 \mathrm{sec})$. Increased polyspiking (i.e., multiple population spikes) in the BSP1/neuropsin knock-out mice is shown by arrows. Arrowheads, time of afferent stimulation. $B$, Time course of the appearance of polyspikes during repetitive stimulation (amplitude of the second spike expressed as a percentage of the first population spike) in slices from BSP1/neuropsin knock-out mice (open circles; $n=5$ ) and from wild-type littermate controls (closed circles; $n=9)$. A significant increase $(p<0.05)$ in the extent of polyspiking was found in BSP1/neuropsin knock-out mice. There were no significant differences in other measures of neuronal excitability in wild-type (WT) and BSP1 mutant (M) mice (this figure; Fig. 5); these parameters were the following ( $n=6$ in each case): resting membrane potential (WT, $-68 \pm 3 \mathrm{mV} ; \mathrm{M},-65 \pm 2 \mathrm{mV}$ ), cell input resistance (WT, $73 \pm 10 \mathrm{M} \Omega ; \mathrm{M}, 68 \pm 16 \mathrm{M} \Omega$ ), and spike frequency adaptation measured in terms of the number of action potentials fired in response to a $+0.4 \mathrm{nA}, 1$ sec current step delivered at the resting membrane potential of the neuron (WT, $8 \pm 2$; M, $7 \pm 2$ ).

significantly greater than that in littermate wild-type control slices (knock-out, $n=5$; wild-type, $n=9 ; p<0.05$; Fig. 4).

Potentially, changes in baseline excitability could explain this observation. However, the input-output relationships for fEPSPs in wild-type $(n=6)$ and BSP1/neuropsin $-/-(n=9)$ slices were indistinguishable, as illustrated by the comparison of the ratio of the presynaptic fiber volley size with fEPSP amplitude plotted in Figure $5 A$. Equally, the population spikes recorded in wild-type $(n=6)$ and BSP1/neuropsin knock-out $(n=6)$ hippocampi revealed no genotype-dependent differences in the peak amplitude of the maximal achievable population spike (Fig. $5 B$ ).

These observations suggest that the increase in excitability to sustained $1 \mathrm{~Hz}$ stimulation seen in slices from BSP1/neuropsin $-/-$ mice is an activity-dependent phenomenon. We therefore examined whether this might relate to changes in paired-pulse facilitation that provides the simplest model for activitydependent changes. As expected, paired stimulation within the stratum radiatum over a range of interpulse intervals (from 15 to 


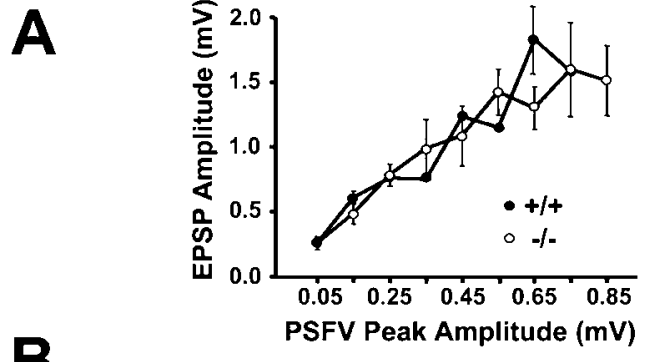

B
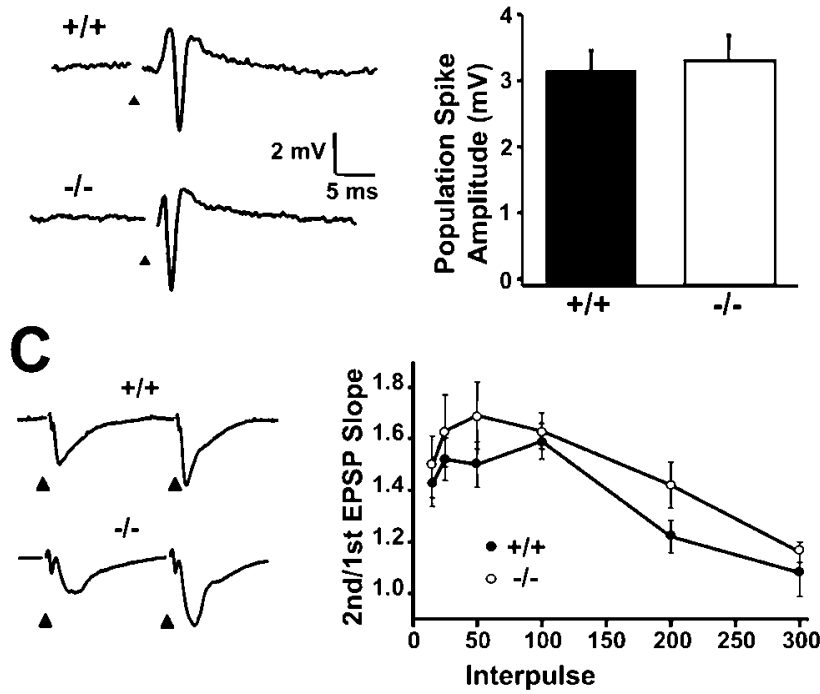

Figure 5. Baseline synaptic transmission in BSP1/neuropsin mutant animals. $A$, Peak-evoked fEPSP amplitudes in response to single-shock stimulation. Amplitudes over a range of stimulus intensities are plotted against the peak amplitudes of the presynaptic fiber volleys (PSFV) immediately preceding the fEPSPs for both wild-type and BSP1/neurop$\sin -/-\operatorname{slices}(n=8$ for each genotype). B, Left, Population spikes in wild-type (top) and BSP1/neuropsin - /- (bottom) slices. Right, Graph depicting the pooled maximum peak amplitude of these responses sampled ( $n=6$ in each case) from wild-type and BSP1 $-/-$ animals. $C$, Left, Synaptic traces showing fEPSPs recorded in response to paired-pulse stimulation delivered at an interstimulus interval of $25 \mathrm{msec}$ in control (top) or BSP1/neuropsin -/- (bottom) slices. Right, Graph recording the magnitude and temporal profile of paired-pulse facilitation (calculated as the slope of the second fEPSP divided by the slope of the first EPSP) in wild-type and BSP1-/- slices ( $n=8$ for each genotype).

$300 \mathrm{msec}$ ) induced paired-pulse facilitation of glutamatemediated fEPSPs in both wild-type and BSP1/neuropsin knockout animals. Whereas the magnitude of this facilitation was not significantly different between the two groups ( $p>0.05$; Fig. $5 C)$, BSP1/neuropsin mutant animals showed a clear trend toward increased facilitation at all interval ranges, although the extent of the observed increase was much smaller than that induced by the $1 \mathrm{~Hz}$ polyspiking train.

\section{Heightened seizure activity on kainate challenge of BSP1/neuropsin mutant mice}

These in vitro data raised the possibility that, during periods of increased neuronal activity, BSP1/neuropsin knock-out animals might display heightened excitability, thus predisposing them to epileptogenesis. To address this, we studied the ability of the glutamate receptor agonist kainic acid to induce convulsions in mutant and control mice. Two (intraperitoneal) doses were tested, and animals were monitored for physiological and behav- ioral changes. Brain histological analysis was performed in parallel.

At the lower dose $(15 \mathrm{mg} / \mathrm{kg})$, all animals irrespective of genotype or sex exhibited a similar temporal profile of physiological seizure activity in response to drug challenge, with onset of seizure activity at $\sim 20 \mathrm{~min}$ after insult in both genotypes. In tissue sections taken at $2 \mathrm{~d}$ after the challenge, histological analysis showed no overt evidence of neuronal cell death in either wild-type or mutant mice. In the absence of cell death, the effects of neuronal excitation can be followed by monitoring the expression of immediate early genes such as the transcription factor c-fos. The spatiotemporal pattern of c-fos induction has been well characterized after kainic acid treatment (La Gal La Salle, 1988; Popovici et al., 1990), and high levels of expression correlate well with susceptibility to cell death in this pharmacological model (Smeyne et al., 1993). Despite the absence of overt cell death, sections taken at $2 \mathrm{hr}$ after the challenge revealed marked induction of c-fos expression in both wild-type and knock-out mice. Interestingly, at this time point, expression levels were markedly increased in BSP1/neuropsin mutant animals in comparison with wild-type littermates (Fig. 6A).

These preliminary results indicated that responsiveness to kainic acid might be enhanced in BSP1/neuropsin mutant animals. This prompted us to monitor the effects of a higher dose (30 $\mathrm{mg} / \mathrm{kg}$ ) of kainic acid and to investigate in more detail immediate early gene expression changes. After intraperitoneal injection, seizures were again recorded in both wild-type and BSP1/ neuropsin mutant animals, and with a similar latency of onset. Both wild-type and mutant animals displayed motion arrest at the same time after the challenge (wild type, $22.42 \pm 1.36 \mathrm{~min}$; mutant, $21.33 \pm 1.84$ min; Students $t$ test, $p>0.05$ ), followed by contemporaneous onset of head and neck muscular myoclonus after the challenge (wild type, $38.33 \pm 3.65 \mathrm{~min}$; mutant, $34.40 \pm$ 3.42 min; Students $t$ test, $p>0.05$ ). However, the later profile of seizure response was clearly different between the two genotypes. In wild-type animals, mild seizures developed into whole-body convulsions in all animals (40-60 min after the challenge) with the majority of wild-type animals (8/10) continuing to display bouts of tonic-clonic seizure for a further $60 \mathrm{~min}$ before normal behavior resumed. In contrast, a subsequent extreme tonic-clonic phase was observed in the majority (7/8) of BSP1/neuropsin mutant mice. This was characterized by rigidity and limb extension and was quickly followed by death (Fig. $6 B$ ). In situ hybridization analysis on postmortem sections revealed that all seizure phases were accompanied by elevated c-fos gene expression; as in the lower dose experiment, this was more widespread and intense in mutant animals than in controls (Fig. 6C).

\section{DISCUSSION}

To explore the function of BSP1/neuropsin, we have investigated the consequences of abolition of its activity in vivo. Because pharmacological agents that selectively interfere with BSP1/ neuropsin activity are not presently available, we used a transgenic approach. Analysis of mice containing an engineered disruption of the gene encoding the serine protease BSP1 (also known as neuropsin) suggests a role for this protease in regulating neuronal excitability within the limbic system. Although patterns of neuronal excitability during embryonic and early postnatal development are believed to be critical for correct wiring of the CNS, BSP1/neuropsin mutant animals were born at the expected Mendelian ratio and displayed no obvious neuroanatomical abnormalities. Gene disruption also failed to affect either 
Figure 6. Immediate early (c-fos) gene expression and physiological response to kainic acid challenge. $A$, c-fos mRNA expression revealed by in situ hybridization in BSP1/neuropsin knock-out $(-/-)$ animals (bottom) and wild-type littermate controls $(+/+$; top $)$. Example expression patterns are shown before (0) and 120 min after injection of kainic acid $(15 \mathrm{mg} / \mathrm{kg}$, i.p.); increased expression is seen in BSP1/neuropsin knock-out mice. $B$, Survival of mice after injection of kainic acid (30 mg/ $\mathrm{kg}$, i.p.). BSP1/neuropsin homozygous knock-out animals $(-1-$; dashed line; $n=$ 8 ) display significant susceptibility compared with wild-type littermate controls $(+/+$; solid line $; n=10)$. $C$, c-fos mRNA expression (in situ hybridization) in BSP1/neuropsin knockout $(-/-)$ animals (bottom) and wild-type littermate controls $(+/+$; top $)$ at various time points (in minutes) after injection of kainic acid $(30 \mathrm{mg} / \mathrm{kg}$, i.p.). Induction of increased expression is demonstrated in BSP1/neuropsin mutant animals at all time points.

hippocampal LTP or spatial navigation in the water maze. However, BSP1/neuropsin mutant hippocampus exhibited a pronounced predisposition to polyspiking during periods of repetitive afferent activity in vitro, and kainic acid challenge in vivo provoked heightened seizure activity that was accompanied by elevated immediate early gene expression throughout the brain and physiological seizure intolerance.

\section{Transgenic studies of seizure}

The results of transgenic studies are often qualified because of the potential role of genetic background in shaping phenotypes. The mouse study group used in our experiments was of C57BL/6 $\times$ 129 mixed genetic background, of note because C57BL/6 mice learn better and are slightly more resistant to kainic acid excitotoxicity than are other strains of mice, e.g., 129 (Schauwecker and Steward, 1997; Royle et al., 1999). In our experiments genetic background influences were minimized by using both wild-type and mutant $(-/-)$ animals of a similar C57BL/6 $\times 129$ hybrid background [with the exception of genes linked to the BSP1/ neuropsin gene disruption (Gerlai, 1996)]. Although we cannot wholly exclude stochastic allelic reassortment and/or allelic variations at a linked locus as contributing factors to the observed phenotype, our results parallel those of several other groups demonstrating a role for serine proteases in the regulation of neuronal activity (Tsirka et al., 1995, 1997; Lüthi et al., 1997).

We have also been concerned that the heightened seizure activity we observe in vivo might be a consequence of alterations in uptake or metabolism of the inducer kainic acid. However, there was no detectable difference in the time of seizure onset between knock-out and control animals. Early phase signs, for instance, the severity of head and neck muscular myoclonus, were indistinguishable between the two groups. This suggests that there is no difference in the rate of uptake of kainate into the brain between mutant animals and controls. Furthermore, the in vitro correlate of epileptiform activity (polyspiking) was seen in the absence of an inducer.
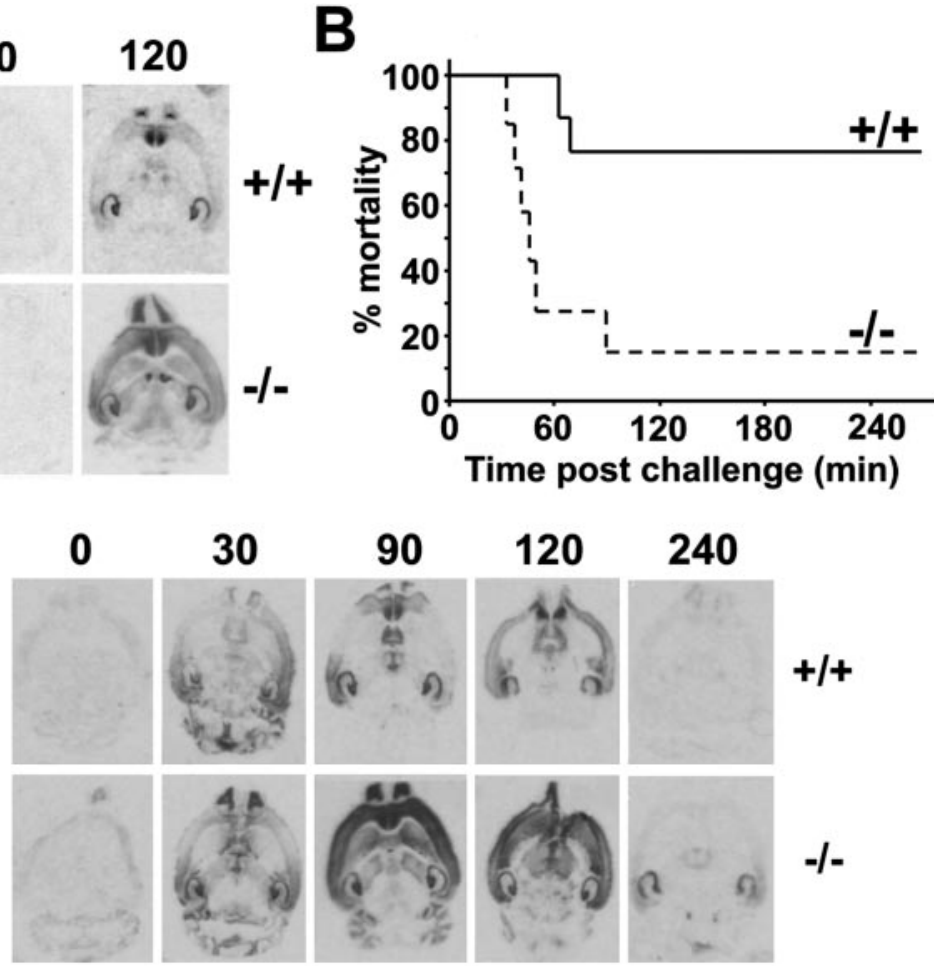

Heightened seizure activity in BSP1/neuropsin knock-out animals is reproduced in many other transgenic models (Frankel, 1999), suggesting that seizure threshold is subject to multiple levels of regulation that together maintain a delicate balance. Notably, >200 genetic loci have been implicated in hereditary epilepsy in humans (Gardiner, 1999, 2000). However, most mouse mutations studied, and inherited epilepsies, predispose to seizure in the absence of explicit challenge. This contrasts with BSP1/ neuropsin mutant animals that appear to be seizure-free in the absence of inducer. There are exceptions, and spontaneous seizure-free mutant mice have been reported in which the gene disruption can either increase (Baraban et al., 1997; Furukawa et al., 1997; Lüthi et al., 1997; Walz et al., 1999; Carrasco et al., 2000) or decrease (Tsirka et al., 1995, 1997; Hamilton et al., 1997; Liu et al., 1999; Jiang et al., 2000) seizure after a challenge.

\section{Gene disruption, regional specificity, and hippocampal function}

The present work also contrasts significantly with these and many transgenic studies in view of the effective regional specificity of the gene disruption. Other family members, exemplified by t-PA, are expressed widely in the nervous system. Brain expression of $\mathrm{BSP} 1 /$ neuropsin is primarily restricted to the hippocampus and amygdala (Chen et al., 1995; Davies et al., 1998). Thus the observed phenotype may selectively reflect primary dysfunction originating in limbic areas and not, for example, in the cortex and other brain areas (but the activity of which may be subservient to inputs from the hippocampus and amygdala).

Within the hippocampus itself, the failure of BSP1/neuropsin gene disruption to affect either hippocampal LTP or spatial navigation contrasts with the established roles of other family members in these processes. Although a recent report using in vivo administration of monoclonal antibodies or antisense oligonucleotides to BSP1/neuropsin suggested that these experimental manipulations reduce early phase LTP (Komai et al., 2000), sustained potentiation was maintained, although at a slightly 
reduced level. At first sight these results appear to contradict those of the present study. However, it was reported that low concentrations of recombinant neuropsin facilitated LTP whereas higher concentrations inhibited (Komai et al., 2000); this could agree with the trend for a slight facilitation of LTP in BSP1/ neuropsin knock-out animals reported here.

\section{Possible mechanism of BSP1/neuropsin action}

The mechanism by which BSP1/neuropsin regulates epileptogenic activity is not known. Polyspikes, such as those we observe in BSP1/neuropsin mutant slices, have been ascribed to activitydependent disinhibition of excitatory synaptic transmission and concurrent NMDA receptor activation and may provide a measure of inhibitory tone (Dingledine and Korn, 1985; Thompson and Gähwiler, 1989). BSP1/neuropsin could facilitate the efficacy of inhibitory, predominantly GABAergic, afferents within the hippocampus. A small but reproducible increase in paired-pulse facilitation, without alteration in fEPSP or population spike amplitude, accords with this interpretation but does not exclude other mechanisms, such as alterations in cellular processes controlling glutamate release or postsynaptic glutamate receptor function.

Although no gross morphological defects were noted in the knock-out animals, high expression of BSP1/neuropsin throughout development (Chen et al., 1998) could be compatible with a role in determining the fine structural organization of brain circuitry during embryogenesis. Formally, therefore, our studies do not exclude the possibility that the observed phenotype might be caused by a developmental abnormality rather than by an absence of BSP1 expression in the adult.

A great diversity of ion channels and neurotransmitter receptors have been implicated in the pathophysiology of epilepsy (Frankel, 1999; Gardiner, 1999, 2000). The specific target for BSP1/neuropsin remains to be established; indeed, BSP1/neuropsin may exert its effects via catalyzed cleavage of target proteins that themselves regulate receptor/channel function. Although some pathways of proteolytic regulation appear to operate intracellularly (Bi et al., 1998), BSP1/neuropsin harbors a secretion signal sequence and is more likely to act outside the cell. Extracellular proteolysis is generally held to increase seizure activity, as reported for trypsin, plasmin, and thrombin (Yamada and Bilkey, 1993; Mizutani et al., 1996; Lee et al., 1997). Reported modulation of GABA and NMDA channels by proteolytic activity (Mizutani et al., 1996; Gingrich et al., 2000) may operate, indirectly, via a family of protease-activated receptors (PARs). Although these are generally activated by thrombin, PAR-2 was maximally activated by trypsin/tryptase-like proteases (for review, see Gingrich and Traynelis, 2000). BSP1/neuropsin is of this type and, in view of its abundance and restricted distribution, is a strong candidate for a regulator of PAR-2 activation in the hippocampus; PAR-2 activity in cultured hippocampal neurons has been reported, but expression in vivo remains to be confirmed (Smith-Swintosky et al., 1997).

Nevertheless, although it is often assumed that brain serine proteases are required to be enzymatically active to exert their effects, there are precedents for nonenzymatic regulation. For instance, microglial activation by t-PA activation proceeds via a nonproteolytic mechanism (Rogove et al., 1999), whereas t-PAmediated protection against zinc neurotoxicity is insensitive to enzyme inhibition (Kim et al., 1999). It is possible that BSP1/ neuropsin acts by binding to specific receptor targets in the brain.
Further work will be required to establish the in vivo target(s) for BSP1/neuropsin.

Whereas the mechanism of BSP1/neuropsin action remains to be elucidated, the phenotype of the mutant animals confirms an important role for this enzyme in vivo. Together, our data suggest a role for BSP1/neuropsin in inhibiting neuronal excitability, particularly under insult conditions. Reports that kindling and oxidative stress cause an upregulation of BSP1/neuropsin mRNA (Akita et al., 1997; Chen et al., 1998) may support this suggestion.

\section{BSP1/neuropsin, seizure, and hippocampal control of cortical activation}

The properties of BSP1/neuropsin mutant mice may also illuminate hippocampal control of cortical activity. Although BSP1/ neuropsin is expressed predominantly in the hippocampus, amygdala, and adjoining brain regions (Chen et al., 1995; Davies et al., 1998), kainate-induced neuronal hyperactivity (reflected in c-fos expression) was seen throughout the brain of mutant animals. This reiterates the pathophysiology of human epilepsy in which focal discharges, originating commonly in the vicinity of the hippocampus, lead to global brain activity (Gastaut, 1970) and further emphasizes the limbic (and particularly hippocampal) control of cortical activity that may underlie some aspects of declarative memory encoding and recall (Squire et al., 1984).

Although our results suggest an important role for BSP1/ neuropsin under insult conditions, human epileptic seizures are often precipitated by physiological and/or environmental stimuli that are otherwise innocuous. We do not exclude the possibility that BSP1/neuropsin might play a role in dampening the onset of epileptiform activity under normal physiological conditions. Spontaneous seizures were not noted in BSP1/neuropsin mutant animals, but seizure activity can be difficult to detect, particularly if it occurs rarely. Experiments with nonpharmacologic epileptogenic stimuli [including auditory stimuli (Ross and Coleman, 2000)] may be warranted. Because our results argue that BSP1/ neuropsin may regulate seizure activity, it remains to be investigated whether pharmacologic agents modulating the activity of hippocampal BSP1/neuropsin (or its substrates) might be of therapeutic value in some forms of epilepsy.

\section{REFERENCES}

Akita H, Matsuyama T, Iso H, Sugita M, Yoshida S (1997) Effects of oxidative stress on the expression of limbic-specific protease neuropsin and avoidance learning in mice. Brain Res 769:86-96.

Bailey CH, Kandel ER (1993) Structural changes accompanying memory storage. Annu Rev Physiol 55:397-426.

Baraban SC, Hollopeter G, Erickson JC, Schwartzkroin PA, Palmiter RD (1997) Knock-out mice reveal a critical antiepileptic role for neuropeptide Y. J Neurosci 17:8927-8936.

Baranes D, Lederfein D, Huang YY, Chen M, Bailey CH, Kandel ER (1998) Tissue plasminogen activator contributes to the late phase of LTP and to synaptic growth in the hippocampal mossy fiber pathway. Neuron 21:813-825.

Bi X, Chen J, Baudry M (1998) Calpain-mediated proteolysis of GluR1 subunits in organotypic hippocampal cultures following kainic acid treatment. Brain Res 781:355-357.

Calabresi P, Napolitano M, Centonze D, Marfia GA, Gubellini P, Teule MA, Berretta N, Bernardi G, Frati L, Tolu M, Gulino A (2000) Tissue plasminogen activator controls multiple forms of synaptic plasticity and memory. Eur J Neurosci 12:1002-1012.

Carrasco J, Penkowa M, Hadberg H, Molinero A, Hidalgo J (2000) Enhanced seizures and hippocampal neurodegeneration following kainic acid-induced seizures in metallothionein-I + II-deficient mice. Eur J Neurosci 12:2311-2322.

Chen ZL, Strickland S (1997) Neuronal death in the hippocampus is promoted by plasmin-catalyzed degradation of laminin. Cell 91:917-925.

Chen ZL, Yoshida S, Kato K, Momota Y, Suzuki J, Tanaka T, Ito J, Nishino H, Aimoto S, Kiyama H (1995) Expression and activity- 
dependent changes of a novel limbic-serine protease gene in the hippocampus. J Neurosci 15:5088-5097.

Chen ZL, Momota Y, Kato K, Taniguchi M, Inoue N, Shiosaka S, Yoshida S (1998) Expression of neuropsin mRNA in the mouse embryo and the pregnant uterus. J Histochem Cytochem 46:313-320.

Davies BJ, Pickard BS, Steel M, Morris RG, Lathe R (1998) Serine proteases in rodent hippocampus. J Biol Chem 273:23004-23011.

Dingledine R, Korn SJ (1985) Gamma-aminobutyric acid uptake and the termination of inhibitory synaptic potentials in the rat hippocampal slice. J Physiol (Lond) 366:387-409.

Frankel WN (1999) Detecting genes in new and old mouse models of epilepsy: a prospectus through the magnifying glass. Epilepsy Res 36:97-110.

Frey U, Müller M, Kuhl D (1996) A different form of long-lasting potentiation revealed in tissue plasminogen activator mutant mice. J Neurosci 16:2057-2063.

Furukawa K, Fu W, Li Y, Witke W, Kwiatkowski DJ, Mattson MP (1997) The actin-severing protein gelsolin modulates calcium channel and NMDA receptor activities and vulnerability to excitotoxicity in hippocampal neurons. J Neurosci 17:8178-8186.

Gardiner RM (1999) Genetic basis of the human epilepsies. Epilepsy Res 36:91-95.

Gardiner RM (2000) Impact of our understanding of the genetic aetiology of epilepsy. J Neurol 247:327-334.

Gastaut H (1970) Clinical and electroencephalographical classification of epileptic seizures. Epilepsia 11:102-113.

Gerlai R (1996) Gene-targeting studies of mammalian behavior: is it the mutation or the background genotype? Trends Neurosci 19:177-181.

Gingrich MB, Traynelis SF (2000) Serine proteases and brain damage: is there a link? Trends Neurosci 23:399-407.

Gingrich MB, Junge CE, Lyuboslavsky P, Traynelis SF (2000) Potentiation of NMDA receptor function by the serine protease thrombin. J Neurosci 20:4582-4595.

Gualandris A, Jones TE, Strickland S, Tsirka SE (1996) Membrane depolarization induces calcium-dependent secretion of tissue plasminogen activator. J Neurosci 16:2220-2225.

Hamilton SE, Loose MD, Qi M, Levey AI, Hille B, McKnight GS, Idzerda RL, Nathanson NM (1997) Disruption of the m1 receptor gene ablates muscarinic receptor-dependent $\mathrm{M}$ current regulation and seizure activity in mice. Proc Natl Acad Sci USA 94:13311-13316.

Huang Y-Y, Bach ME, Lipp H-P, Zhuo M, Wolfer DP, Hawkins RD, Schoonjans L, Kandel ER, Godfraind J-M, Mulligan R, Collen D, Carmeliet D (1996) Mice lacking the gene encoding tissue-type plasminogen activator show a selective interference with late-phase longterm potentiation in both Schaffer collateral and mossy fiber pathways. Proc Natl Acad Sci USA 93:8699-8704.

Jiang D, Akopian G, Ho YS, Walsh JP, Andersen JK (2000) Chronic brain oxidation in a glutathione peroxidase knockout mouse model results in increased resistance to induced epileptic seizures. Exp Neurol 164:257-268.

Kim YH, Park JH, Hong SH, Koh JY (1999) Nonproteolytic neuroprotection by human recombinant tissue plasminogen activator. Science 284:647-650

Komai S, Matsuyama T, Matsumoto K, Kato K, Kobayashi M, Imamura K, Yoshida S, Ugawa S, Shiosaka S (2000) Neuropsin regulates an early phase of Schaffer-collateral long-term potentiation in the murine hippocampus. Eur J Neurosci 12:1479-1486.

La Gal La Salle G (1988) Long-lasting and sequential increase of c-fos oncoprotein expression in kainic acid-induced status epilepticus. Neurosci Lett 88:127-130.

Lee KR, Drury I, Vitarbo E, Hoff JT (1997) Seizures induced by intracerebral injection of thrombin: a model of intracerebral hemorrhage. J Neurosurg 87:73-78.

Liu H, Cao Y, Basbaum AI, Mazarati AM, Sankar R, Wasterlain CG (1999) Resistance to excitotoxin-induced seizures and neuronal death in mice lacking the preprotachykinin A gene. Proc Natl Acad Sci USA 96:12096-12101.

Lüthi A, van der Putten H, Boteri FM, Mansuy IM, Meins M, Frey U, Sansig G, Portet C, Schmutz M, Schröder M, Nitsch C, Laurent J-P, Monard D (1997) Endogenous serine protease inhibitor modulates epileptic activity and hippocampal long-term potentiation. J Neurosci 17:4688-4699.

Madani R, Hulo S, Toni N, Madani H, Steimer T, Muller D, Vassalli JD
(1999) Enhanced hippocampal long-term potentiation and learning by increased neuronal expression of tissue-type plasminogen activator in transgenic mice. EMBO J 18:3007-3012.

Mansour SL, Thomas KR, Capecchi MR (1988) Disruption of the proto-oncogene int- 2 in mouse embryo-derived stem cells: a general strategy for targeted mutations to non-selectable genes. Nature 336:348-352.

Mizutani A, Saito H, Matsuki N (1996) Possible involvement of plasmin in long-term potentiation of rat hippocampal slices. Brain Res 739:276-281.

Morris RG, Garrud P, Rawlins JN, O'Keefe J (1982) Place navigation impaired in rats with hippocampal lesions. Nature 297:681-683.

Nakagami Y, Abe K, Nishiyama N, Matsuki N (2000) Laminin degradation by plasmin regulates long-term potentiation. J Neurosci 20:2003-2010.

Nehls M, Kyewski B, Messerle M, Wladschütz R, Schüddekopf K, Smith AJH, Boehm T (1996) Two genetically separable steps in the differentiation of thymic epithelium. Science 272:886-889.

Popovici T, Represa A, Crepel V, Barbin G, Beaudoin M, Ben-Ari Y (1990) Effects of kainic acid-induced seizures and ischemia on c-foslike proteins in rat brain. Brain Res 536:183-294.

Qian Z, Gilbert ME, Colicos MA, Kandel ER, Kuhl D (1993) Tissueplasminogen activator is induced as an immediate-early gene during seizure, kindling and long-term potentiation. Nature 364:453-457.

Rogove AD, Siao C, Keyt B, Strickland S, Tsirka SE (1999) Activation of microglia reveals a non-proteolytic cytokine function for tissue plasminogen activator in the central nervous system. J Cell Sci 112:4007-4016.

Ross KC, Coleman JR (2000) Developmental and genetic audiogenic seizure models: behavior and biological substrates. Neurosci Biobehav Rev 24:639-653.

Royle SJ, Collins FC, Rupniak HT, Barnes JC, Anderson R (1999) Behavioral analysis and susceptibility to CNS injury of four inbred strains of mice. Brain Res 816:337-349.

Schauwecker PE, Steward O (1997) Genetic determinants of susceptibility to excitotoxic cell death: implications for gene targeting approaches. Proc Natl Acad Sci USA 94:4103-4108.

Selkoe DJ (1991) The molecular pathology of Alzheimer's disease. Neuron 6:487-498.

Smeyne RJ, Vendrell M, Hayward M, Baker SJ, Miao GG, Schilling K, Robertson LM, Curran T, Morgan JI (1993) Continuous c-fos expression precedes programmed cell death in vivo. Nature 363:166-169.

Smith AJ, De Sousa MA, Kwabi-Addo B, Heppell-Parton A, Impey H Rabbitts P (1995) A site-directed chromosomal translocation induced in embryonic stem cells by Cre-loxP recombination. Nat Genet 8:376-385.

Smith-Swintosky VL, Cheo-Isaacs CT, D'Andrea MR, Santulli RJ, Darrow AL, Andrade-Gordon P (1997) Protease-activated receptor-2 (PAR-2) is present in the rat hippocampus and is associated with neurodegeneration. J Neurochem 69:1890-1986.

Squire LT, Cohen NJ, Nadel L (1984) The medial temporal lobe and memory consolidation: a new hypothesis. In: Memory consolidation (Eingertner E, Parker E, eds), pp 185-210: Hillsdale, NJ: Erlbaum.

Thompson SM, Gähwiler BH (1989) Activity-dependent disinhibition. I. Repetitive stimulation reduces IPSP driving force and conductance in the hippocampus in vitro. J Neurophysiol 61:501-511.

Tsirka SE, Gualandris A, Amaral DG, Strickland S (1995) Excitotoxininduced neuronal degeneration and seizure are mediated by tissue plasminogen activator. Nature 377:340-344.

Tsirka SE, Rogove AD, Bugge TH, Degen JL, Strickland S (1997) An extracellular proteolytic cascade promotes neuronal degeneration in the mouse hippocampus. J Neurosci 17:543-552.

Vandenberghe W, Van Den Bosch L, Robberecht W (1998) Tissue-type plasminogen activator is not required for kainate-induced motoneuron death in vitro. NeuroReport 9:2791-2796.

Vassalli J-D, Sappino A-P, Belin D (1991) The plasminogen activator/ plasmin system. J Clin Invest 88:1067-1072.

Walz R, Amaral OB, Rockenbach IC, Roesler R, Izquierdo I, Cavalheiro EA, Martins VR, Brentani RR (1999) Increased sensitivity to seizures in mice lacking cellular prion protein. Epilepsia 40:1679-1682.

Yamada N, Bilkey DK (1993) Induction of trypsin-induced hyperexcitability in the rat hippocampal slice is blocked by the $N$-methyl-Daspartate receptor antagonist, MK-801. Brain Res 624:336-338. 